\title{
Sosyal Bilgiler Dersi Öğretim Programında Eskiçağ Konularının Öğretimsel Kavramlar Açısından Analizi
}

\author{
Aysun AYNUR YILMAZ ${ }^{1}$
}

Gönderim Tarihi: 15.09 .2021

Kabul Tarihi: 18.10 .2021

Yayın Tarihi: 19.10 .2021

Öz: Sosyal bilgiler, Milli Eğitim Bakanlı̆̆ı 2008 yılı müfredatındaki tanıma göre; öğrenme alanlarının bir tema veya ünite çerçevesinde birleştirilmiş, sosyal ve fiziki ortamlarıyla etkileşim içinde olan, geçmişi, bugünü ve geleceği inceleyerek birçok disiplini içerisinde barındıran bir ilköğretim dersidir. Bu dersin kapsamında olan Tarih dersi, geçmişin anlamlandırılmasında ve günümüz için aydınlatılmasında önemli rol alan bir bilim dalıdır. Tarih öğretiminde, tarihle ilgili kavramların öğrencilere verilmesi önemlidir. Ayrıca tarihimizin bütünüyle öğretilmesi açısından tarihi çağların başlangıcı olan Eskiçağ tarihi konularına yer verilmesi, tarihsel bütünlük oluşturması açısından büyük önem taşımaktadır. 5. sınıf Sosyal bilgiler programının kazanımları, ders içeriği ve açıklamaları bu çalışmada analiz edilmiştir. Araştırma, doküman analizi yöntemiyle yapılmıştır. 5.sınıf öğretim programındaki kazanımları incelenmiştir. Araştırmanın sonucunda Sosyal bilgiler dersi 2018 yılı öğretim programında müze kanıtları, tarihsel süreçte önem, deliller, değişimdeki farklılıklar ve süreklilik, sebep ve sonuçlar, tarihsel perspektif açısından önemli kavramların yer aldığı, aynı zamanda fazlaca yer verildiği gözlemlenmiştir. Araştırmanın sonuçlarına göre; Sosyal bilgiler öğretim programlarında günümüze uygun bir şekilde yeniden yapılacak güncelleme çalı̧malarında, tarih disiplininin yöntemsel kavramlarının ön planda tutulması açısından görüşler ortaya konmuştur.

Anahtar Kelimeler: Sosyal bilgiler öğretim programı, yöntemsel kavramlar, tarihsel düşünme becerileri.

\section{In The Teaching Program Of Social Studies Analysis Of Ancient Issues In Terms Of Educational Concepts}

\begin{abstract}
Social studies, according to the definition of the Ministry of education of Turkish Republic 2008 curriculum learning areas of the unit in the framework of a theme or merged, social and physical interaction with the environment, Past, Present and future by examining a number of disciplines in hosting an elementary course. The history course, which is part of this course, is a branch of science that plays an important role in making sense of the past and illuminating it for the present. In history teaching, it is important to give the concepts related to history to the students. In addition, in terms of teaching our history in its entirety, it is of great importance to include ancient history subjects, which are the beginning of historical ages, in terms of establishing historical integrity. 5th grade social studies program achievements, course, content and explanations were analyzed in this study. This research has been done with the document analysis method and the 5th grade learning gain. As a result of the research, it was observed that museum objects, importance in the historical process, evidence, differences in change and continuity, causes and consequences, important concepts in terms of historical perspective were included in the 2018 curriculum of the Social Studies Course. According to the results of the research, opinions were put forward in terms of keeping the methodical concepts of the discipline of history at the forefront in the work of updating social studies curriculum in accordance with the present day.
\end{abstract}

Keywords: Social studies curriculum, methodological concepts, historical thinking skills

\section{GíRISS}

Dünya'daki gelişmelere paralel olarakgünümüz insanı da,hızlı bir değişim ve dönüşümü yaşamaktadır. Bilim, teknoloji, tarisel süreç vb. alanlarla birlikte eğitim sistemi de sürekli bir yenilenme çabası içerisindedir.

Örgün eğitimin en önemli amaçlarından birisi de eğitim alan öğrencileri sosyal hayata hazırlamaktır. Bir çok ülkede olduğu gibi Türkiye'de de bu hazırlık ilk öğretimden itibaren ortaöğretim süresince sosyal bilgiler dersi konuları içerisinde yer almaktadır. Sosyal bilgiler içerik

\footnotetext{
${ }^{1}$ Necmettin Erbakan Üniversitesi, Türkiye, aysaynur@yahoo.com, ORCID: 0000-0002-3758-1692
} 
olarak; tarih, coğrafya, ekonomi ve sosyoloji gibi konuları kapsamaktadır. Bu bilgiler sayesinde çocuklar hayata hazırlanmakta ve yaşamları boyunca karşılaştıkları sorunlara çözümler üretebilmektedirler. Deveci'nin (2005)'de belirttiği gibi, öğrenciler Sosyal bilgiler dersi ile vatandaşlık gerekliliğini geliştirmek amacıyla sosyal bilimler ile insani bilimlerin örtüştürüldüğü bir alandir.

MEB 2018 Sosyal bilgiler öğretim programında, tarih ve kültürel miras ile ilgili özel amaçları arasında şu açıklamalara yer verilmektedir; kendi kültürünü ve tarihini meydana getiren temel unsurları ve süreci kavrayarak bir milli bilinç ve kültürel mirası koruma, geriştirme bilinci içerisinde olmaları ve farklı tarihler - farklı mekanlardaki tarihsel kanıtları araştırarak, bunlar arasındaki benzerlilikleri ve değişiklikleri fark etmeleri beklenmektedir. Zaman içerisindeki değişimi ve dönüşümleri fark etmeleri ve bunula birlikte analitik bir düşünme biçimine sahip olmaları hedeflenmektedir.

Her yeni eğitim programı bir önceki eğitim programının yetersizlikleri ya da eksiklikleri giderilerek güncellenmektedir. Eğitim-Öğretim programları, hedeflenen belirli bir amaca öğrencileri ulaştırmak için oluşturulmuştur ve bu eğitimler belirli bir plan dâhilinde yürütülmektedir (Ertürk, 1984). Eğitim programı, öğrencinin içinde bulunduğu toplum ve çevre ile birlikte geleceğe ulaşma amacıyla tasarlanan bütün eğitim çalışmalarını kapsamaktadır. Eğitim programında bulunan alan öğretim programı da, öğretim süreç ve aşamalarında düzeyleri farklı sınıf ve disiplinlerde öğrencilere aktarılacak konular ve çeşitli örnekleri bünyesinde barındıran öğretim faaliyetlerinin bütününü içermektedir (Demirel, 2013).

Barr'a (1977) göre, Sosyal Bilgiler dersinin iki ana öğesi olmalıdır. Bunlar; sorumlu birer vatandaşlar olarak topluma katılmalarını sağlamak ve bireylerin dünyayı anlamasına destek olmaktır. Ancak Sosyal bilgiler dersi disiplin olarak zengin bir içerik barındırdığı için, içeriği ve pedagojisi, çeşitli sosyal ve politik olaylardan büyük ölçüde etkilenmektedir (Ross, Mathison \& Vinson, 2014). Öğretim programları, güncellemeyi gerektiren durumlar oluştuğu zaman; toplumsal ihtiyaçlar, teknolojik, bilimsel ve sosyal gelişmelerin gerektirdiği durumlarda güncellenir. Günümüzde Türkiye'de kullanılan Sosyal Bilgiler Öğgretim Programı 2018'de güncellenmiştir.

Program içerisinde bulunan "Kültür ve Miras Ünitesi” özelinde tarih odaklı olan, kültür ve kültürel mirası bu ders kapsamında ön plana taşıyan bir konudur. Türk kültürünü kapsayan esas noktalar dikkate alındığında, kültürel oluşumun korunması ve de geliştirilmesine yardımcı olacak bir millî bilincin oluşturulması hedeflenmektedir. Bu bağlamda öğrenciler, kültürel öğeler üzerinden kendi toplumunu başka toplumlardan ayıran farklılıkların varlığını anlayacaktır (MEB 2018).

İnsanlık tarihinin en uzun dönemini kapsayan Eskiçağ tarihi, tarih biliminin de başlangıcında yer almaktadır. Uluslararası alanda Eskiçă̆ kavramı Eduard Meyer ile başlamış ve yazdığı eserle (Geschichte des Altertums) günümüzde de geçerliliğini koruyan bu alanda bir anlayış oluşturmuştur. İlk başlarda Eskiçağ kavramı, sadece Hellen ve Roma toplumlarını kapsamıştır. 19.yy.da, Eskiçağ kavramı; Mısır yazısının çözümlenmesiyle, Mısır ve Eski Önasya uygarlıkları da eklenerek hem zaman açısından hem de kapsam açısından genişletilmiştir. Günümüzde ise Eskiçağ tarihi içerik olarak, Akdeniz ve Önasya kültürleri ve bu kültürle direk ilişkileri olan toplumları ve yazının bulunuşu ile başlayan ve Roma'nın Akdeniz'deki bitişine (M.Ö.3000-2800) ve M.S.7. yy.dan itibaren Ortaçă̆’a kadar olan süreyi kapsar (İplikçioğlu, 1997).

Tarih bilimi insanlığa, nerden geldiği ve nereye gittiği konusunda bir rehberdir. Bu rehberi insan 
ne kadar iyi anlar ve yorumlarsa o kadar hayata karşı donanımlı olacak ve hata yapma olasılığını azaltacaktır. Zaten eğitimin amacı da yetişmekte olan gençlerin gerçek yaşamda gerekli olan becerileri edinmesidir, yani onları hayata ve sosyal yaşama hazırlamaktır. Sosyal bilgiler dersi konuları içerisinde yer alan kültürel miras ve Eskiçağ tarihi konuları, tarisel süreç içerisinde insanlığın hangi aşamalardan ve değişimlerden geçtiğini anlamaları ve yorum yapabilmeleri açısından oldukça önemlidir. Tarih bir bütündür ve Eskiçağ tarihi insanlık tarihinin yüzde doksanını kapsamaktadır. Bu kadar geniş kapsamına rağmen tarihin diğer dönemlerine oranla bu döneme ait bilgiler daha azdır ve alanla ilgili yapılan bilimsel çalışmalara göre de (arkeolojik çalışmalar) değişebilmektedir. Öğrencilerin tarihte meydana olayları anlayıp yorum yapabilmeleri için de tarih biliminin başlangıcında yer alan, insanlık tarihinin gelişiminin en yoğun olduğu bir dönem olan Eskiçağ tarihi ve kültürünün anlaşılır bir biçimde verilmesi gerekmektedir. Kapsam olarak günümüzden çok uzak bir dönem olması ve derslerde daha çok sözel anlatımlarla bu konuların işlenmesi öğrenciler için bu konuların anlaşırlırolmalarını zorlaştırmaktadır. Bu nedenle bu konuların farklı öğretim yöntemler ile öğrenciler için dikkat çekiciliği artırılmalıdır. Bu konuda, Sosyal Bilgiler programları üzerinde çalışanlara büyük sorumluluklar getirmektedir.

Bu çalışmanın amacı; 2018 yılında Sosyal bilgiler dersi öğretim programı, 5. Sınıf Eskiçağ tarihi ve kültürüne yönelik kazanımların ve bu konuda kullanılan kavramların analizi ve konuyu ifade etme durumunun analizidir. Çalışmanın alt amaçları ise şu şekildedir:

1. 5. Sınıf Sosyal Bilgiler Dersi 2. Ünitesi Öğretim Programında yer alan "Yöntemsel” Kavramlar nelerdir?, Yeterli midir?

2. 5. Sınıf Sosyal Bilgiler Dersi 2. Ünitesi Öğretim Programında yer alan "Kazanımlarda Kullanilan Kavramlar" nelerdir? Yeterli midir?

3. 5. Sınıf Sosyal Bilgiler Dersi 2. Ünitesi Ders Kitabında Yer Alan “Kazanımlarda Kullanılan Kavramlar" nelerdir?

\section{YÖNTEM}

Araştırmada, nitel araştırma yöntemleri kapsamında doküman analizi yöntemi kullanılarak çalışılmıştır ve ders içeriğinde belirlenen tarihin, bu alana ait yöntemsel kavramların olup olmadığ1 ve eğer varsa bu noktaların üniteler bazında dağılımının ne şekilde olduğu incelenmiştir. Doküman inceleme, geçmişteki olguların izlerini taşıyan resim, film, tarihsel kalıntılar, yazılı kaynaklar vb. yapıtları, birtakım yazılı materyalleri analiz etmek için kullanılan nitel araştırma yöntemidir (Karasar, 2008). Bu çalışmada, 5. sınıf Sosyal bilgiler ders programındaki Eskiçağ tarihi konularının yer aldığı kazanımlarda ve ders içeriğinde belirlenen tarihin bu alana ait yöntemsel kavramları (tarihsel önem, tarihsel kanıt, değişim ve süreklilik, sebep-sonuç, tarihsel perspektif açısından) kazandırmaya dönük bir yaklaşımın var olup olmadığı perspektifiyle analiz edilmiştir.

\section{Verilerin Toplanmasi}

Milli Eğitim Bakanlığı tarafından yayınlanan ilköğretim 5. sınıf Sosyal bilgiler dersi öğretim programı bünyesinde yer alan Eskiçağ tarihi konusuyla ilgili kazanımlar, etkinlik örnekleri ve açıklamalar veri kaynaklarını oluşturmaktadır. 2018 yılında Sosyal bilgiler dersi öğretim programı yeniden düzenlenmiştir. 5. sınıf Sosyal bilgiler öğretim programının seçilmesinin nedeni Eskiçağ tarihi konularını içeriğinde barındırmasıdır. 5. sınıf düzeyinde yer alan "2.Ünite: Kültür ve Miras" ünitesi Eskiçağ tarihi konularını içerdiği için anahtar ünite olarak belirlenmiştir. Bu açıdan temel düzeyde kavramların yer alıp almadığının detaylı analizi için 5. sınıf Sosyal bilgiler dersi öğretim 
programı analiz için seçilmiştir ve Öztürk, Kafadar (2020)’’n da belirttiği gibi aşağıda yer alan aşamalar takip edilmiştir;

Belgelere erişebilme; Birinci etapta Sosyal bilgiler dersine ait öğretim programı edinilmiştir. İlgili öğretim programına, Talim Terbiye kuruluna ait resmi web sitesi üzerinden erişilmiştir.

Orjinalliği (özgünlüğü) kontrol etme; Sosyal bilgiler dersi öğretim programının orjinalliği Talim Terbiye kurulunun resmi web sitesine bakılarak kontrol edilmiştir.

Belgeleri ( dökümanları) anlama; mevcut belge içerikleri konuya ilişkin araştırma sorularıyla ilişkilendirilmiştir.

Veriden örneklem seçme; 5. Sınıf Sosyal bilgiler öğretim programı kapsamında incelemesi (analizi) yapılan metinler üzerinde örnekleme yapılmadan bütün aşamaların tasnifi yapılmıştır.

Sınıflandırmaların geliştirilmesi; Bu aşamada, konu ile ilgili sorularla sınıflandırma çalışmaları yapılmıştır.

\section{Verilerin Analizi}

Bu çalışmada İlköğretim 5. sınıf Sosyal bilgiler dersi öğretim programında (MEB, 2018) elde edilen veriler, içerik analizİ yöntemiyle analiz edilmiştir. Yıldırım ve Şimşek'in (2011) belirttiği; temaların oluşturulması, verilerin kodlanarak düzenlenmesi, tespitlerin tanımlanarak yorumlanması süreçleri izlenmiştir.5. sınıf Sosyal bilgiler dersi öğretim programının uygulanmasıyla ilgili açıklamalar kısmında "Bu öğrenme alanı çalışılırken, kültürel mirasa duyarlılık ve estetik değerlerle Türkçeyi doğru bir şekilde etkili ve güzel kullanarak, araştırma gibi yeteneklerin de öğrenciler tarafından kazanılması sağlanmalıdır" ifadesine yer verilmiştir. Bu nedenle, öncelikle programdaki ünite kazanımlarında yöntemsel kavramların ne oranda vurgulandığı ve nasıl yer verildiği analiz edilmiştir.

Sonraki aşamada, öğretim programı ve ders kitabı ilişkilendirme ve ilgili açıklayıcı işlenecek konuların sınırlarını belirleyen ifadelerin neler olduğu (MEB, 2018) yöntemsel kavramlarla ilgili bir ilişkilendirmenin olup olmadığı incelenmiştir. Programda kazanımlara uygun olması açısından hazırlanan ders içerikleri ve etkinlikler öğretmen için rehber niteliğinde olmasına rağmen, öğretmene fikir verdiğinden bu bölümde yöntemsel kavramları kazandırmaya yönelik olup olmadığı açısından analiz edilmiştir. 5. Sınıf Sosyal bilgiler dersi öğretim programında yer alan kazanımlar ve ders kitabı, (Demircioğlu, 2009) bahsettiği gibi tarih öğretiminde başarıyı yakalamış ülkelerden İngiltere'de, İngiliz Tarih öğretim programı incelendiği zaman, programın içermesi gereken genel hedeflerin öğrencilere tarihsel düşünme becerilerini kazandıracak şekilde düzenlendiği dikkati çekmektedir. Bu beceriler ise;

- Kronolojik anlama

- Geçmişteki değişim, insan ve olayları anlama ve bilme

- Tarihsel yorum

- Tarihsel soruşturma, araştırma

- Organizasyon ve iletişimdir.

Ayrıca bunlara bağlı olarak, sebep-sonuç ilişkisi kurma, kültürel değerlere önem verme ve koruma gibi kavramlar kodlanmıştır. Öncelikle programda doğrudan yöntemsel kavram ifadeleri aranmış ve kodlanmıştır. 5. sınıf Sosyal bilgiler dersi 2. Ünitesinde, Tarih ders programında tarihsel perspektif alma düşüncesi bulunmamakta fakat bakış açısı ifadesiyle, perspektif alma kavramının 
da kazanılması hedeflendiği ders içeriği ve açılamalar, bu düşünceyle kodlanmıştır. Bu yaklaşımla toplanan açık içeriğin yanında saklı içeriğin de tespit edilerek kodlanmasına önem verilmiştir. Bu maksatla, yöntemsel kavramlara yönelik anahtar kelimeler de kodlanmıştır. Bu kodlar aşağıdaki tabloda belirtilmiştir. Ayrıca, “Gündelik yaşamda yer alan kültürel ögelerin süreklilik ve değişimi üzerinde durulur.

Tablo 1. 5. Sınıf Sosyal Bilgiler Dersi Öğretim Programında yer alan 2. Ünite (Kültürel Miras) Kazanımlarının Yöntemsel Kavramlar Açısından Analiz İşlemlerinde Kullanılan Kodlar

\begin{tabular}{|c|c|c|}
\hline Kazanım & Kavram & Kod \\
\hline $\begin{array}{l}\text { SB.5.2.1.Anadolu ve Mezopotamya } \\
\text { kültürlerinin insanlık tarihine sağladığı } \\
\text { önemli katkıları, mevcut kalıntılardan } \\
\text { hareket ederek fark eder. }\end{array}$ & $\begin{array}{l}\text { Kültürel } \\
\text { miras }\end{array}$ & $\begin{array}{l}\text { Tarihsel önem, katkı, günümüze olan } \\
\text { etkileri }\end{array}$ \\
\hline $\begin{array}{l}\text { SB.5.2.2. Etrafındaki tarihi mekanları, } \\
\text { eserleri, doğal varlık ve nesneleri tanıtır. }\end{array}$ & $\begin{array}{l}\text { Tarih } \\
\text { bilinci }\end{array}$ & $\begin{array}{l}\text { Tarihsel soruşturma, araştırma } \\
\text { Geçmişteki değişim, insan ve olayları } \\
\text { anlama ve bilme }\end{array}$ \\
\hline $\begin{array}{l}\text { SB.5.2.3. Yaşadı̆̆ı çevre ile, ülkenin başka } \\
\text { yerlerinin kültürel farklılıklarını } \\
\text { karşılaştırarak bunlar arasındaki benzer ve } \\
\text { değişik unsurları belirler. }\end{array}$ & $\begin{array}{l}\text { Tarih } \\
\text { duyarlılığ } 1\end{array}$ & $\begin{array}{l}\text { Tarihsel yorum, koruma, gelecek } \\
\text { nesillere aktarma }\end{array}$ \\
\hline $\begin{array}{l}\text { SB.5.2.4. Kültürel ögelerin, insanların bir } \\
\text { arada yaşamasındaki rolünü analiz eder. }\end{array}$ & $\begin{array}{l}\text { Tarihi } \\
\text { mekân }\end{array}$ & $\begin{array}{l}\text { Kanıt, kaynaklardan çıkarımda } \\
\text { bulunma, eser, metin, kalıntı }\end{array}$ \\
\hline $\begin{array}{l}\text { SB.5.2.5. Günlük hayattaki kültürel ögelerin } \\
\text { tarihi gelişimini değerlendirir. }\end{array}$ & $\begin{array}{l}\text { Tarihsel } \\
\text { zaman }\end{array}$ & $\begin{array}{l}\text { Değişim, değişme, gelişim, gelişmeler, } \\
\text { süreklilik, süreç, yüzyll, dönem } \\
\text { (eskiçağ, uygarlık, medeniyet), } \\
\text { kronoloji }\end{array}$ \\
\hline
\end{tabular}

\section{Geçerlik ve Güvenirlik}

$\mathrm{Bu}$ çalışmada geçerlik ve güvenirlik kapsamında yapılan işlemler şu şekildedir; dokümanlara ulaşma aşamasında 5. sınıf Sosyal bilgiler dersi öğretim programına ülkenin eğitimle ilgili resmi web sitesinden ulaşılmıştır. Bu yolla dokümanların orijinallikleri test edilmiştir. Araştırmanın verileri analiz edilme sürecinde ilk aşamada kodlamalar yapılmıştır. Analiz sürecinde kodlamaların ve sınıflamaların doğru yapılıp yapılmadı̆̆ı benzer araştırmalarla karşılaştırılmış ve iki program geliştirme uzmanı tarafından kontrol edilmiştir.

\section{BULGULAR}

$\mathrm{Bu}$ bölümde yer alan 2. ünite (Kültürel Miras) kazanımlarının yöntemsel kavramlar açısından analiz sonuçları verilmiştir. Programda, kazanılması düşünülen değerler, bir takım becerilerle birlikte yetkinlikler açısından bütünlüğü sağlayan bir yaklaşımla sade bir içeriğe işaret etmektedir. Kültür ve kültürel mirası ön planda tutan bu öğrenme alanı temelde tarih odaklı bir anlayışa sahiptir. Milli bilincin oluşturulması, geliştirilmesi ve korunması düşüncesiyle Türk kültürünü oluşturan temel unsurlardan hareket edilmiştir. Öğrenciler böylece, bir toplumu başka 
toplumlardan ayıran değerlerin kültürel ögeler olduğunu anlayacaklardır. Bununla birlikte, kültürümüzün diğer dünya kültürlerine renk ve zenginlik katacağı kavratılır. (MEB, 2018).

\section{Birinci Alt Amaçlara İlişkin Bulgular}

\section{Sınıf Sosyal Bilgiler Dersi 2. Ünitesi Öğretim Programında yer alan “Yöntemsel” Kavramlar}

5. Sınıf Sosyal bilgiler dersi öğretim programı Türkiye'de 2018'den itibaren uygulamakta olan Sosyal bilgiler dersi öğretim programının değerlendirildiği bu araştırmada ulaşılan bulgular şu şekildedir:

Programda yer alan kazanım - ders içerikleri - açıklamalar kısmı, Sosyal bilgiler disiplininin yöntemsel kavramları açısından analiz edilmiştir. Analiz sonuçları ise; 5. Sınıf Sosyal bilgiler dersi öğretim programında 5 kazanım içinde; kültürel miras kavramı içerik olarak yer almaktadır. Fakat, mevcut kavramlar vurgulanırken açıkça yeterli olmadığı düşünülmektedir. Programda, kazanılan bilgi ve becerilerin öğrenciler tarafından içselleştirilebilmesi için, ünite bazında kazandıklarının diğer ünitelerde de kullanmaları sağlanmalıdır (Harut, 2020).

\section{İkinci Alt Amaçlara İlişkin Bulgular}

\section{Sınıf Sosyal Bilgiler Dersi 2. Ünitesi Öğretim Programında yer alan "Kazanımlarda Kullanılan Kavramlar"}

Programda, “öğrencilerin bu ünitede kazandığı bilgi ve becerileri diğer ünitelerde de kullanmaları sağlanmalıdır. Bu sayede kazanılan bilgi ve beceriler öğrenciler tarafından içselleştirilebilecektir" şeklinde açıklamada bulunulmuştur.

Kültür ve Miras ünitesinin 1.kazanımı olan " Somut kalıntılarından yola çıkarak Anadolu ve Mezopotamya uygarlıklarının insanlık tarihine önemli katkılarını fark eder" kazanımının açıklamalar kısmında yöntemsel kavramlardan "kültür ve miras", "tarih bilinci" "tarihsel kalıntılar" kavramlarının geçtiği tespit edilmiştir. Kavramlar yeterli ve açıklayıcı değildir. 2. kazanımda "Çevresindeki doğal varlıklar ile tarihî mekânları, nesneleri ve eserleri tanıtır" bu sayede geçmişle günümüz arasında bağ kurabilir, bu kazanımda da" tarih bilinci", "tarihi değerleri koruma"' gibi kavramları öğrenebilmektedir.

Kazanımda; "Ülkemizin çeşitli yerlerinin kültürel özellikleri ile yaşadığı çevrenin kültürel özelliklerini karşılaştırarak bunlar arasındaki benzer ve farklı unsurları belirler". Kazanımın açıklamasında yöntemsel kavramlardan "çıkarımda bulunma", "tarihsel yorum", "tarihsel soruşturma", "'araştırma" geçtiği tespit edilmiştir. 4. kazanımda "Kültürel ögelerin, insanların bir arada yaşamasındaki rolünü analiz eder". Yöntemsel kavramlardan "tarihsel analiz", "insani olayları anlama ve bilme", "çıkarımda bulunma" gibi kavramları içermektedir. 5.kazanımda "günlük yaşamdaki kültürel unsurların tarihî gelişimini değerlendirir".

Kazanımın açıklamasında yöntemsel kavramlardan "çıkarımda bulunma", "geçmişle günümüz arasında bağ kurma" gibi kavramları içermektedir. Sosyal bilgiler dersi bünyesindeki metodoloji açısından anahtar olarak kabul edilen bu ünitede yöntemsel kavramların kazanım ve içerik açısından açık bir şekilde vurgulanmadığı düşünülmektedir.

\section{Üçüncü Alt Amaçlara İlişkin Bulgular}

5. Sınıf Sosyal Bilgiler Dersi 2. Ünitesi Ders Kitabında Yer Alan “Kazanımlarda Kullanılan Kavramlar"

Ünitenin; "Uygarlıkları Tanıyoruz" başlığında, "kronoloji", "tarih şeridi" kavramları ile 
uyuşmaktadır ancak, 1.kazanımla tarihsel düşünme becerilerinden "kronolojik düşünme becerisine" uygundur. 1.kazanımı olan " somut kalıntılarından yola çıkarak Anadolu ve Mezopotamya uygarlıklarının insanlık tarihine önemli katkılarını fark eder", uygarlıkları tek tek, örnekler verilerek açılanmıştır. Ülkemizin güzellikleri adlı ikinci başlığında " tarihi eserler ", "tarihi mekânlar", "tarihi nesneler" vurgulanmaktadır. Zengin kültürümüz isimli üçüncü başlıkta ise; "kültürel değerler", '"kültürel zenginlik", "'milli mücadele", "milli bayramlar", ,"milli birlik ve beraberlik" kavramlarını içermektedir.

Ortak değerlerimiz adlı 4. başlıkta ve 5. başlık Geçmişten günümüze kültürümüz adlı başlıkta, "kültürel zenginlik", "kültürel miras", tarihsel önem, katkı, günümüze olan etkileri gibi kavramlar vurgulanmaktadir.

\section{TARTIŞMA VE SONUÇ}

Türkiye'de, 2018 yılında güncellenen Sosyal bilgiler dersi öğretim programına bütüncül bir bakış açısıyla yaklaşırsak; Sosyal bilgiler dersi programı dört boyutta değerlendirilmiştir. Öğretim programı incelendiği zaman amaçlar boyutunda perspektif, amaçlar ve özel amaçlardan oluşmaktadır. Bu çalışmada ise; 5. sınıf ikinci ünitesini kapsayan kazanımlar ele alınmıştır. Programda, yetkinlik başlı̆̆ı altında yer alan eğitim sistemimiz, bütünleşmiş bilgi, beceri ve davranış yetkinliklerine sahip özellik ve karakterde bireyleri yetiştirmeyi amaçlar maddesi, sosyal ve vatandaşlıkla ilgili yetkinlikleri ( kişisel - kişilerarası ve diğer kültürler arası yetkinlikler); bireylerin değişen toplum ve iş yaşamına etkili ve yapıcı bir konumda katılmalarına imkan sağlayacak; ilgili durumlarda problemleri çözecek şekilde donatılmasını sağlayan bir yaklaşımı kapsar.

Sosyal bilgiler dersi öğretim programı kapsamında, insan, kültürel miras, toplum - yer ve yaşam alanları, üretim, vatandaşlık kültürel ilişkiler, bağlantılar ve etkileşimler gibi benzeri kavramlar üzerinden öğrenme alanları yer almaktadır.

2005 yılında yayınlanan programa ait öğrenme alanları ile karşılaştırıldığında bunlardan başka, idare ve toplum, sosyal gruplar, güç ve kurumlar, zamanın sürekliliği ve değişim kavramları da Sosyal bilgiler öğretim programında mevcut bulunmaktadır (Ocak, Kocaman, 2021).

Programın özel amaçlarına farklı bir açıdan baktığımızda, “değişim ve sürekliliği algılamak"konusunda bir amaç oluşması aynı zamanda zıtlık oluşturmaktadır. NCSS'e (2010) göre bu programlar, geçmişe ait tüm değerleri yeni nesillere aktaran çalışmalar olmalıdır.

Ulusları, toplumların tarihsel bağlamda süreklilik ve değişimlerini, insanın varoluş süreçlerini anlamak ve kavrayabilmek, geçmişi araştırmak, incelemek ve doğru veriler 1şı̆̆ında yorumlamakla mümkündür.

Tarisel anlamda yapılan analiz ve araştırmalar, toplumlar, kurumlar, temel değerler ve yeniliklerle birlikte gelenek ve göreneklerdeki değişim süreçleri konularında bilgiler edinilmesini sağlar.

Geçmiş dönemlere dair mevcut bilgiler, o zaman dilimlerine ait olayları, nedenleri, gelişme süreçlerini ve bunlara bağlı olarak da sebep-sonuç ilişkilerini doğru analiz etmemize yardımcı olacak temel veriler olacaktır.

NCSS'in (2010) de “zaman, süreklilik ve değişim” kavramlarını içeren yaklaşımları, Sosyal bilgileri oluşturan konular kapsamında bulunması, mevcut öğrenme alanları için önemli olduğunun göstergesidir. 
Sosyal bilgiler NCSS (2010) öğrenme alanı içeriği ile 2018 de yayınlanan Sosyal bilgiler dersi öğretim programı içerik çalışmasında büyük benzerlikler vardır.

Programda kazanımlar; tüm sınıf düzeylerinde öğrenme alanları bakımından biribirine yakın süreçler izlemiştir.

Öztürk, Kafadar, (2020)' a göre; programda temel becerilerin; kavram olarak zamanla değişim ve sürekliliği algılama ve anlama, eleştirel ve yenilikçi düşünme, kronolojik yaklaşım, empati ve iletişim konularında aktif olmanın yanı sıra, gözlem ve karar verme yeteneğini geliştirmesi söz konusu olacaktır. Bunlarla birlikte; tablo, grafik çizme - yorumlama, problem çözme, araştırmalarla işbirliği ve sosyal katılım, anadili olan Türkçeyi doğru ve etkili bir şekilde kullanma, öz denetim, mekanı algılama ve anlamlandırma, dijital vatandaşlık ve medya okur-yazarlığı yanı sıra kanıt kullanma, konum analizi ve girişimcilik konularının olduğu belirtilmektedir.

Bireyleri toplumsal ve siyasal kavram ve anlayışlara ilişkin bilgilere, vatandaşlık ile ilgili yetkinlik; demokratik ve aktif katılıma bağlı olarak medeni yaşama tam anlamıyla katılmaları için donatmaktadır (MEB,2018). “Kültürel farklılık ve ifade: Görsel ve sahne sanatları, müzik, edebiyat ve farklı kitle iletişim araçları kullanılarak, fikir - deneyim ve yaratıcı duyguların bir biçimde ifade edilmesinin öneminin taktiridir". açıklamalarındaki kazanımların ders kitaplarında uyumlu olduğu görülmektedir.

Belirtilen temel beceriler ise; empati, eleştirel düşünme, gözlem, işbirliği, iletişim, kanıt kullanma, zaman ve kronolojiyi anlamadır. Belirtilen değerler ise; aile birliğine önem verme, dayanışma, duyarlılık, dürüstlük, saygı, sevgi, sorumluluk, vatanseverlik, yardımseverlik değerleriyle eşleşmektedir.

Bu sebeple, kavramlara bağlı ögelerin tespit edilerek açılanması, kavramların bütüncül bir yaklaşımla eksiksiz öğrenilmesine bilişsel açıdan katkılarda bulunarak daha nitelikli öğrenmelerin oluşmasını destekleyecektir.

Sosyal bilgiler dersi için 2018 yılında yayınlanan öğretim programı incelendiğinde, içeriğe ilişkin yalnızca kazanımlar ve buna bağlı olarak da açıklamalar yer almakla birlikte yeterli olmadığı anlaşılmaktadır (Öztürk, Kafadar, 2020).

\section{Öneriler}

Eskiçağ tarihi konularına dair daha fazla merak uyandırıp, öğrencinin ilgisini bu alana yönlendirerek, geçmişe dair düşünme günümüzdeki olay ve kavramlarla mantıksal düzlemde doğru ilişkiler kurması da söz konusu olabilecektir.

Zamanla yenilenecek olan sosyal bilgiler dersine ait öğretim programlarında yer alan öğrenme alanlarının her birinde yeterli düzeyde açıklamaların olmasıyla birlikte daha anlaşılır ve kazanım sayılarının artması söz konusu olacaktır. Bu noktaların etkili bir şekilde ortaya konulması program açısından önemli olmakla birlikte aynı zamanda öğretim içeriklerini de zenginleştirecektir.

Araştırmalarda, yurt dışında yayınlanan (Fransa, ABD) eğitim programları içeriklerinde, etkinlikler konusunda daha fazla bir yaklaşımın olduğu görülmektedir. Bu bağlamda, yeni hazırlanacak olan Sosyal bilgiler öğretim programında etkinlik örneklerinin çoğaltılması programı daha etkili ve güçlü kılacaktır. Ayrıca, öğretim programı kapsamındaki ne öğretileceğinin yanı sıra, yurt dışındaki örneklerinde olduğu gibi, içerik bölümlerindeki nasıl ve niçin öğretileceğine dair bilgilendirici açıklamaların da bulunması, daha bilinçli bireylerin yetiştirilmesine katkı sağlayabilir. 
Ders programı içerisinde bulunan öğrenme alanları ile bağlantılı olarak, kazanımlar ve açıklamaların da çoğaltılarak, her bir öğrenme alanı için daha etkili bir şekilde verilmesi önemlidir. $\mathrm{Bu}$ yaklaşımlarla birlikte, öğrenme alanlarındaki bilgi, beceri ve örneklerin içselleştirilerek daha kalıcı ve değerli hale gelmesi, bilimsel, teknolojik ve sosyal gelişmelerle birlikte yenilenerek daha güçlü yansımaları olacaktır.

Ülkemizde, özellikle Sosyal bilgiler dersi öğretim programı içerisinde yer alan Eskiçağ tarihini kapsayan konulardaki kavramlarla ile ilgili çalışmaların yetersizliği (az oluşu) bu araştırmada örneklendirme yapmamızı zorlaştırmıştır. Bu çalışma ile, söz konusu alan ile ilgili gelecekte yapılacak olan araştırmalara katkı sağlanmaya çalışılmıştır.

\section{KAYNAKLAR}

Barr, R. D., Barth, J. L., \& Shermis, S. S. (1977). Defining the social studies (No. 51). Arlington, VA: National Council for the Social Studies.

Demircioğlu, İ. H. (2009). Tarih öğretmenlerinin tarihsel düşünme becerilerine yönelik görüşleri. Milli Ĕ̆itim Dergisi, 39(184), 228-239.

Demirel, Ö. (2013). Eğitimde program geliştirme: Kuramdan uygulamaya. Ankara: Pegem Akademi.

Ertürk, S. (1984). Eğitimde program geliştirme. Hacettepe Üniversitesi Basımevi, Ankara.

Harut,S.B.(2020). Sosyal bilgiler 5. simif ders kitabı. 12.10.2021 tarihinde; https://drive.google.com/file/d/1607gFcjmixrVIvz1PU_MFU_osb4REc7U/view adresinden alındi.

İplikçioğlu, B. (1994). Eskiçă̆ tarihinin ana hatları, İstanbul: Bilim Teknik Yay.

Karasar, N. (2008). Bilimsel araştırma yöntemi, Nobel Akd. Yay., 9. Basım, Ankara.

MEB Sosyal Bilgiler Öğretim Programı 2018, Ankara. 15.08.2021 tarihinde Milli Eğitim Bakanlığ1: https://mufredat.meb.gov.tr/Dosyalar/201812103847686-

SOSYAL\%20B\%C4\%B0LG\%C4\%B0LER\%20\%C3\%96\%C4\%9ERET\%C4\%B0M\%20PROGRA $\mathrm{MI} \% 20 . p d f$ adresinden alınd1.

National Council for the Social Studies (NCSS) (2010). https://www.socialstudies.org sitesinden 10.10.2021 tarihinde alınmıştır.

Ocak, G. ve Kocaman, B. (2021), 2018 Yıl1 5. Sınıf sosyal bilgiler dersi öğretim programının değerlendirilmesi, IJOFE, 7 (1), 1-24.

Öztürk, C., \& Kafadar, T. 2018 Sosyal Bilgiler Öğretim Programının Değerlendirilmesi. Trakya Eğitim Dergisi, 10(1), 112-126.

Ross, E.W., Mathison, S. and Vinson, K.D. (2014), Social Studies Curriculum and Teaching in the Era of Standardization. In: The Social Studies Curriculum: Purposes, Problems, and Possibilities (Ed: E. W.Ross), Albany, State University of New York Press

Yıldırım, A. ve Şimşek, H. (2011), Sosyal Bilimlerde Nitel Araştırma Yöntemleri, Seçkin Yay., Ankara. 